\title{
DOCE LUSTROS DE HISTORIA Y DE SERVICIO FACULTAD DE INSTRUMENTACIÓN QUIRÚRGICA
}

Ivonne Acuña López*

La comunidad científica y académica de la Fundación Universitaria de Ciencias de la Salud, del Hospital de San José y de manera especial la Facultad de Instrumentación Quirúrgica, celebran con beneplácito y satisfacción los 60 años de labores dedicados al ejercicio de la docencia.

Difícil hacer una completa y justa reseña de los diferentes momentos, circunstancias y proyectos de esta facultad. No obstante, es un deber hacer un reconocimiento a las personalidades que con abnegado espíritu de servicio y gran compromiso ético y profesional han posicionado nuestra institución. Personajes eméritos que con tesón, prospectiva y eficiencia han construido y llevado al éxito a la facultad:

- La enfermera Celmira Acevedo de Segura, quien en 1950 presentó a la junta directiva del Hospital de San José la propuesta para la creación del programa. El 23 de febrero de 1951 se aprobó la Escuela de Instrumentación Quirúrgica del Hospital de San José y ella fue la primera directora.

- Dr. Roberto Jaramillo Uricoechea, Rector de la Fundación Universitaria de Ciencias de la Salud y gestor incansable del progreso de la misma.

- Dr. Jorge Gómez Cusnir, presidente de la Sociedad de Cirugía de Bogotá desde el año 2000 y quien ha liderado y gestionado diferentes proyectos que son el motor de la Facultad.

Instrumentadora quirúrgica egresada de la Fundación Universitaria de Ciencias de la Salud,especialista en Bioética, con maestría en Educación de la Pontificia Universidad Javeriana, Decana de la Facultad de Instrumentación Quirúrgica, Fundación Universitaria de Ciencias de la Salud.

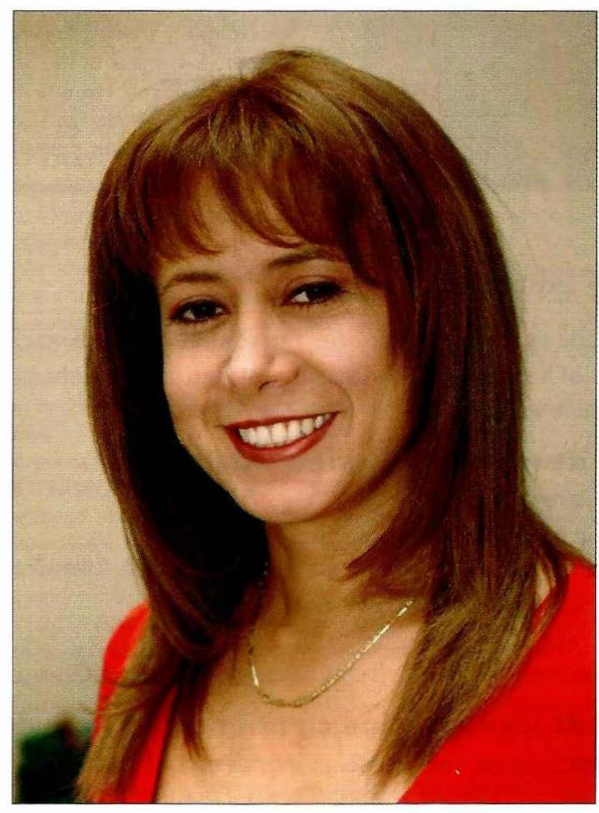

Además, debo destacar la gestión de tantas personas que por su extensa lista, solo les hago llegar un grato saludo de reconocimiento. Al igual un saludo de gratitud a los directores y luego las decanas que han orientado el programa de la facultad en los diferentes momentos.

\section{Hitos académicos de la facultad}

1951 Albores de la facultad.

1979 Se reconoce la profesión como "Técnica profesional intermedio".

1980 Se crea la Fundación Tecnológica de Carreras Paramédicas dirigida por la Sociedad de Cirugía de Bogotá.

1982 El Congreso de la República de Colombia aprueba la profesión de tecnólogas en instrumentación quirúrgica. 
El ICFES otorga la licencia de funcionamiento al programa.

1992 Primera promoción de tecnólogas en Instrumentación Quirúrgica de la Fundación Tecnológica de Carreras Paramédicas.

1996 Creación de la Fundación Universitaria de Ciencias de la Salud.

1998 Luego de realizar los estudios respectivos, las docentes de la Facultad reciben el título de profesionales en Instrumentación Quirúrgica.

2000 Se gradúa la primera promoción de profesionales.

2008 Se realiza el primer diplomado en Central de Esterilización.

2011 Se crea el Fondo de becas "CELMIRA

\section{ACEVEDO DE SEGURA”.}

La permanente dinámica en la gestión, los reconocimientos por parte del Ministerio de Educación, del Senado de la República y del Concejo de Santa Fe de Bogotá, así como los resultados obtenidos en los exámenes de calidad académica en educación superior (ECAES) logrando ocupar los primeros puestos, constituyen los pilares para que hoy se reconozca la labor de la facultad, que además de la formación de la persona se ha interesado en la construcción del conocimiento, enriquecido en forma permanente por la cualificación de los procesos. Mediante la investigación se ha buscado dar soluciones a los diferentes problemas, implementando estrategias para la aplicación de los avances de la ciencia y la tecnología en situaciones simuladas y/o reales, que aportan crecimiento al buen ejercicio de la instrumentación quirúrgica.

Luego de esta sucinta retrospectiva del devenir histórico de nuestra facultad es oportuno dar una mirada hacia nuevos proyectos y realizaciones que continúen ubicando la profesión de Instrumentación Quirúrgica en un destacado puesto de vanguardia por sus logros y la calidad en todas las áreas, así como establecer alianzas nacionales e internacionales para lograr la movilidad académica conducente a la globalización, la creación de programas de posgrado, educación continuada e investigación, para ofrecer mayor y mejor cobertura a estudiantes y egresados. Hay que continuar fortaleciendo, cualificando e integrando diferentes facetas de la vida profesional, como aprender a aprender (esencia pedagógica), aprender a ser (proyecto de vida), aprender a hacer (desarrollo de competencias laborales generales) y aprender a convivir (competencias ciudadanas y de desarrollo solidario), para marcar la diferencia en lo esencial y seguir manteniendo el posicionamiento de los egresados de la facultad.

Imposible terminar sin hacer referencia a los egresados y docentes de esta facultad. Para todos ellos un fraternal saludo y que gracias a su gran labor nuestra profesión cada día es y será más reconocida y sus realizaciones tendrán mayor trascendencia.

Gratitud y reconocimiento para todos en estos 60 años de historia y servicio, en especial a la familia Acevedo Segura que ha creado el Fondo de Becas CELMIRA ACEVEDO DE SEGURA para aquellas estudiantes que por alguna eventualidad comprobada y su excelente rendimiento académico, requieran apoyo económico.

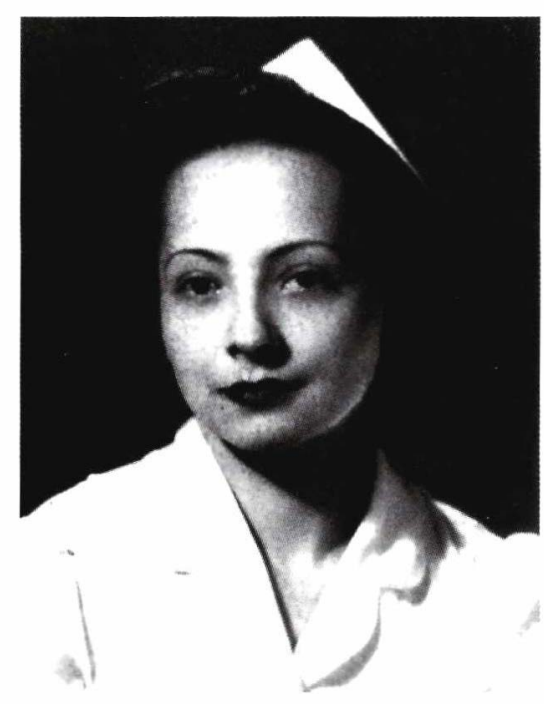

Enfermera Celmira Acevedo de Segura 